\title{
Microbiological pathogen analysis in native versus periprosthetic joint infections: a retrospective study
}

\author{
Sebastian Linke ${ }^{1^{*}} \mathbb{D}$, Alexander Thürmer ${ }^{2}$, Kevin Bienger ${ }^{1}$, Christian Kleber ${ }^{1}$, Petri Bellova', Jörg Lützner ${ }^{1}$ and \\ Maik Stiehler ${ }^{1}$
}

\begin{abstract}
Background: The presence or absence of an implant has a major impact on the type of joint infection therapy. Thus, the aim of this study was the examination of potential differences in the spectrum of pathogens in patients with periprosthetic joint infections (PJI) as compared to patients with native joint infections (NJI).

Methods: In this retrospective study, we evaluated culture-positive synovial fluid samples of 192 consecutive patients obtained from January 2018 to January 2020 in a tertiary care university hospital. For metrically distributed parameters, Mann-Whitney $U$ was used for comparison between groups. In case of nominal data, crosstabs and Chisquared tests were implemented.

Results: Overall, 132 patients suffered from periprosthetic joint infections and 60 patients had infections of native joints. The most commonly isolated bacteria were coagulase-negative Staphylococci (CNS, 28\%), followed by Staphylococcus aureus (S. aureus, 26.7\%), and other bacteria, such as Streptococci (26.3\%). We observed a significant dependence between the types of bacteria and the presence of a joint replacement $(p<0.05)$. Accordingly, detections of CNS occurred 2.5-fold more frequently in prosthetic as compared to native joint infections (33.9\% vs. 13.4\% $p<0.05$ ). In contrast, S. aureus was observed 3.2-fold more often in NJls as compared to PJls (52.2\% vs. $16.4 \%, p<0.05)$.

Conclusion: The pathogen spectra of periprosthetic and native joint infections differ considerably. However, CNS and S. aureus are the predominant microorganisms in both, PJIs and NJIs, which may guide antimicrobial therapy until microbiologic specification of the causative pathogen.
\end{abstract}

Keywords: Joint infection, Pathogen spectrum, Synovial fluid, Prosthesis, Native

\section{Background}

Due to the increase in joint replacement operations [1], PJIs have become a relevant challenge in modern medicine [2]. Regarding NJIs, low incidences of four to ten cases per 100,000 individuals per year have been reported

\section{*Correspondence: Sebastian.Linke@uniklinikum-dresden.de}

${ }^{1}$ University Centre of Orthopaedic, Trauma and Plastic Surgery, University Hospital Carl Gustav Carus Dresden, TU Dresden, Fetscherstraße 74, 01307 Dresden, Germany

Full list of author information is available at the end of the article and a possible increase is still controversial [3, 4]. Nevertheless, both infection types share a high risk for complications, necessitating differentiated diagnostics $[5,6]$.

Patients suffering from PJI frequently show recurrences [7]. Prolonged hospitalization and delayed functional recovery are common consequences and possible reasons for the elevated five-year-mortality rate of up to $26 \%$ [4, 6]. NJIs are no less demanding, as they cause a significant risk for secondary osteoarthritis and permanent joint damage, leading to loss of function in about $40 \%$ of cases $[6,8]$.

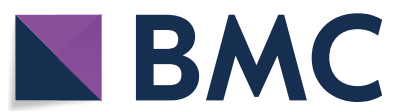

(c) The Author(s) 2021, corrected publication 2022. Open Access This article is licensed under a Creative Commons Attribution 4.0 International License, which permits use, sharing, adaptation, distribution and reproduction in any medium or format, as long as you give appropriate credit to the original author(s) and the source, provide a link to the Creative Commons licence, and indicate if changes were made. The images or other third party material in this article are included in the article's Creative Commons licence, unless indicated otherwise in a credit line to the material. If material is not included in the article's Creative Commons licence and your intended use is not permitted by statutory regulation or exceeds the permitted use, you will need to obtain permission directly from the copyright holder. To view a copy of this licence, visit http://creativecommons.org/licenses/by/4.0/. The Creative Commons Public Domain Dedication waiver (http://creativecommons.org/publicdomain/zero/1.0/) applies to the data made available in this article, unless otherwise stated in a credit line to the data. 
An adequate initial empiric antibiotic therapy is therefore crucial. However, treating the predominant pathogens can be a challenge. Regardless of the infection type, blood cultures often remain inconclusive [9] and possible contamination in analyses of tissue may provide falsenegative results. Awareness of the expected pathogens in periprosthetic, as well as in native joint infections could therefore accelerate diagnostic procedures and increase the patient's outcome.

In implant-associated infections, biofilm formation is a characteristic pathomechanism. It weakens the effect of the physiological immune response and the effect of an antimicrobial therapy as well [10]. Certain bacteria, such as Staphylococcus epidermidis (S. epidermidis) and $S$. aureus, show a high capacity for biofilm formation [11]. Therefore, their detection rate in PJIs is comparatively high $[12,13]$. In native joints, the emergence of an infection depends as much on the success or failure of the local and systemic immune response. Accordingly, highly potent virulence factors and signaling mechanisms characteristic of $S$. aureus increase the likelihood of infection [14]. The literature considers both CNS and S. aureus as predominant causatives in periprosthetic and native joint infections as well $[12,15]$. Evidence for differing pathogen distributions, such as a dominance of $S$. aureus in NJIs and of CNS in PJIs, is weak [10, 16]. Therefore, it remains inconclusive, whether the presence of a joint replacement influences the type of causative bacteria in joint infections, which could necessitate different empiric antibiotic therapies. To this end, we retrospectively examined differences in the spectrum of pathogens based on synovial fluid analyses in patients with PJI as compared to those with NJI.

\section{Materials and methods}

\section{Study design and endpoints}

In this retrospective level 3 study, we screened all microbial synovial fluid analyses performed at our tertiary care university hospital from January 2018 to January 2020. Inclusion criteria were a positive culture result in the microbiological analysis and that the samples originated from a closed joint aspiration. We then investigated whether the patient in question had subsequently undergone surgery for a joint infection and whether laboratory markers of a joint infection were present at the time of aspiration, such as an increased CRP concentration in the serum and a raised leukocyte count in the synovial fluid. If both criteria were not fulfilled, the exclusion criteria were met.

The samples were classified depending on the presence or absence of a prosthesis in the infected joint. Intergroup differences in the pathogen spectrum of synovial fluid samples were the primary endpoint. In addition, the infection sites and the number of mixed infections were assessed. Age, gender, previous immunosuppressive therapy, diabetes mellitus or renal insufficiency were analyzed in the context of patient characteristics. Due to the anonymized data collection and the retrospective design, no ethics application was necessary for the study conduct according to Saxonian legislation.

\section{Defined categories of isolated pathogens}

The spectrum of isolated pathogens was stratified into five groups, based on clinical aspects and the number of detections. The group of CNS included S. epidermidis, $S$. capitis, S. hominis, S. lugdunensis and S. caprae. Since it is the only coagulase-positive Staphylococcus and because of its high detection rate, we defined $S$. aureus a single pathogen class. Within the group of Enterobacterales, we subsumed the detected species of E. coli, Enterobacter cloacae complex, Proteus spp. and Klebsiella spp.. Obligatory anaerobic pathogens were Anaerococcus spp., Bacteroides fragilis, Clostridium difficile and Fusobacterium mortiferum. The last group consists of other pathogens, such as different species of Enterococci and Streptococci, Pseudomonas aeruginosa, and other, rarely detected microorganisms.

\section{Statistics}

With respect to the patients' age being a metrically distributed parameter, a non-normal distribution was proven using the Shapiro-Wilk test, and Mann-Whitney $\mathrm{U}$ was applied for intergroup comparison. For nominal data, such as the infection sites and the isolated pathogen types, crosstabs and Chi-squared tests were implemented using the contingency coefficient $(C)$ to confirm significant differences. Regarding associations between the presence of renal insufficiency or diabetes mellitus and possible differences in the pathogen distribution, a binary logistic regression analysis was performed. In general, the confidence interval was set to $95 \%$.

\section{Results}

Study population and patient characteristics

During the observation period of 2 years, 192 patients were diagnosed culture-positive by synovial fluid analyses (Table 1). Of these, 132 had periprosthetic joint infections and 60 suffered from native joint infection. On average, patients with PJI were significantly older as compared to patients with NJI (72 vs. 59.5 years, $p<0.01$ ). However, no differences in gender distribution occurred.

In the cohort investigated, the most common localization of joint infection was the hip (50\%), followed by the knee (39.5\%), and the shoulder (3.6\%) joint. Regarding joint replacements, infections occurred more frequently in the hip (65.2\%) compared to the knee (29.5\%) joint. An 
Table 1 Study population, patient characteristics, microbial detection rates, and infection sites

\begin{tabular}{|c|c|c|c|c|}
\hline & PJI & $\mathrm{NJI}$ & $P$ & Total \\
\hline Patients (n [\%]) & $132[68.8]$ & $60[31.2]$ & & $192[100]$ \\
\hline \multicolumn{5}{|l|}{ Patient characteristics } \\
\hline Age $($ median $\pm S D)$ & $72 \pm 12.1$ & $59.5 \pm 24.7$ & $<0.01$ & $66.3 \pm 18.4$ \\
\hline \multicolumn{5}{|l|}{ Sex } \\
\hline Male (n [\%]) & $68[51.5]$ & $40[66.7]$ & & $108[56.3]$ \\
\hline Female (n [\%]) & $64[48.5]$ & 20 [33.3] & & $84[43.7]$ \\
\hline Immunosuppression (n [\%]) & $11[8.3]$ & $8[13.3]$ & & 19 [9.9] \\
\hline Diabetes mellitus (n [\%]) & $41[31.1]$ & $10[16.7]$ & 0.036 & $551[26.6]$ \\
\hline Renal insufficiency (n [\%]) & $39[29.5]$ & $12[20]$ & & $51[26.6]$ \\
\hline \multicolumn{5}{|l|}{ Microbial detection rates } \\
\hline Pathogen detections (n [\%]) & 165 [71.1] & $67[28.9]$ & & 232 [100] \\
\hline Mixed infections (n [\%]) & $33[25]$ & $7[11.7]$ & & $40[20.8]$ \\
\hline \multicolumn{5}{|l|}{ Infection sites } \\
\hline Hip & 86 [65.2] & $10[16.7]$ & $<0.01$ & $96[50]$ \\
\hline Knee & $39[29.5]$ & $37[61.7]$ & $<0.01$ & $76[39.6]$ \\
\hline Shoulder & $1[0.75]$ & $6[10]$ & & $7[3.6]$ \\
\hline Ankle & $4[3]$ & $2[3.3]$ & & $6[3.1]$ \\
\hline Elbow & $1[0.75]$ & $5[8.3]$ & & $6[3.1]$ \\
\hline Wrist & $1[0.75]$ & $0[0]$ & & $1[0.5]$ \\
\hline
\end{tabular}

SD standard deviation

opposite result was observed in native joints with $61.7 \%$ of infections being detected in the knee, and $16.7 \%$ in the hip joint. Overall, 19 patients received immunosuppressive treatment with a rate independent of the presence of an endoprosthesis. The rate of diabetes mellitus was significantly higher in the PJI group as compared to the NJI group (31.1\% vs. $16.7 \%, p=0.036)$, while no differences occurred regarding the existence of renal insufficiency.

\section{Pathogen spectrum in synovial fluid analyses}

In 192 samples, we isolated 232 pathogens with 165 and 67 of them belonging to the PJI and the NJI group, respectively (Table 1). Hence, 33 (25\%) mixed infections occurred in periprosthetic joints and seven (11.7\%) in native joints. In total, 32 different pathogens were isolated. Staphylococcal species were by far the most frequently detected pathogens with 83 (50.3\%) positive results in the PJI and $44(65.7 \%)$ in the NJI group (Table 2). With a detection rate of $62 / 232$ (26.7\%), $S$. aureus was the most commonly isolated pathogen, followed by $S$. epidermidis, being identified in 48 cases (20.7\%). There was one case of oxacillin-resistant $S$. aureus (MRSA) in the overall study population, detected in a PJI patient.

Infections caused by $S$. aureus were 3.2 -fold more frequent in NJIs (52.5\%) as compared to PJIs (16.4\%, CI 95\%). Contrarily, infections with $S$. epidermidis occurred 4.5-fold more often in PJIs (26.7\%) as compared to NJIs (6\%, CI 95\%). In general, there were significant differences in the distribution of pathogen types, depending on the presence or absence of a prosthesis in the infected joint $(C=0.47, P<0.05)$. With reference to the pathogen classes, CNS $(n=65,28 \%)$ were most common (Fig. 1), followed by $S$. aureus (see above), other pathogens $(n=61,26.3 \%)$ and Enterobacterales $(n=36,15.5 \%)$. Infections with CNS occurred more frequently in PJIs $(n=56,33.9 \%)$ as compared to NJIs $(n=9,13.4 \%)$. Of these CNS detections, 37 (66.1\%) and four (44.4\%) were oxacillin-resistant in the PJI and NJI group, respectively, without a significant intergroup difference regarding their detection rate.

Furthermore, we detected a 2.5-fold increased rate of infections with Enterobacterales in periprosthetic joints $(n=31,18.8 \%)$ as compared to native joints $(n=5,7.5 \%$, CI 95\%). The differences regarding anaerobic and other pathogens were minor. Overall, the distribution of pathogen classes differs significantly between PJIs and NJIs $(C=0.363, p<0.05)$.

There was no significant between the presence of renal insufficiency or diabetes mellitus and the pathogen spectrum in the entire study population as well as in the subgroups.

\section{Discussion}

In this study, we detected significant differences in the pathogen spectrum of PJIs as compared to NJIs. Staphylococcus aureus was isolated 3.2 times more often in infections of native joints. Contrarily, infections with CNS were 2.5 times more common in PJIs. Besides staphylococcal species, we also found a 2.5 -fold increased detection rate of Enterobacterales in prosthetic as compared to native joint infections.

These results are in accordance with the literature, as CNS are considered the predominantly involved microorganisms in PJIs with a range in the detection rate of $27-75 \%[17,18]$. Regarding infections of native joints, $S$. aureus is a main causative in about $39-60 \%$ of cases [19, 20]. Despite the existence of these data being in line with the results of the present study, there is also some contradictory evidence for a prevalent role of S. aureus in PJIs [21]. Siu et al. reported a $44.1 \%$ detection rate of $S$. aureus in 34 PJIs, of which $70 \%$ were late-onset infections, without specific cause clarification. The data situation regarding infections with Enterobacterales in native joints is still indecisive, whereas a detection rate of $15 \%$ is reported for implant associated joint infections [22]. In the present study, a large proportion of $66.1 \%$ of CNS were oxacillinresistant in PJIs, and the literature describes rates of up to $77.8 \%$ [22]. However, most of these studies were not 
Table 2 Total pathogen spectrum in PJIs and NJIs (n [\%])

\begin{tabular}{|c|c|c|c|}
\hline Pathogen & PJI $(N=165)$ & $\mathrm{NJI}(\mathrm{N}=67)$ & Total $(\mathrm{N}=232)$ \\
\hline Staphylococcus spp. & 83 [50.3] & $44[65.7]$ & $127[54.7]$ \\
\hline Oxacillin-resistant Staphylococcus spp. & $38\left[45.8^{*}\right]$ & $4\left[9.1^{*}\right]$ & $42\left[33.1^{*}\right]$ \\
\hline Staphylococcus aureus & $27[16.4]$ & 35 [52.2] & $62[26.7]$ \\
\hline Oxacillin-resistant Staphylococcus aureus & $1\left[3.7^{*}\right]$ & $0\left[0^{*}\right]$ & $1\left[1.6^{*}\right]$ \\
\hline Coagulase-negative staphylococci & 56 [33.9] & $9[13.4]$ & $65[28]$ \\
\hline Oxacillin-resistant CNS & $37\left[66.1^{*}\right]$ & $4\left[44.4^{*}\right]$ & $41\left[63.1^{*}\right]$ \\
\hline Staphylococcus epidermidis & $44[26.7]$ & $4[6]$ & $48[20.7]$ \\
\hline Staphylococcus capitis & $4[2.4]$ & $2[3]$ & $6[2.6]$ \\
\hline Staphylococcus hominis & $3[1.8]$ & $2[3]$ & $5[2.2]$ \\
\hline Staphylococcus lugdunensis & $3[1.8]$ & $1[1.5]$ & $4[1.7]$ \\
\hline Staphylococcus caprae & $2[1.2]$ & $0[0]$ & $2[0.9]$ \\
\hline Enterobacteriaceae & 31 [18.8] & $5[7.5]$ & $36[15.5]$ \\
\hline Escherichia coli & $14[8.5]$ & $3[4.5]$ & $17[7.3]$ \\
\hline Enterobacter cloacae complex & $11[6.7]$ & $1[1.5]$ & $12[5.2]$ \\
\hline Klebsiella spp. & $2[1.2]$ & $1[1.5]$ & $3[1.3]$ \\
\hline Proteus spp. & $4[2.4]$ & $0[0]$ & $4[1.7]$ \\
\hline Obligatory anaerobic pathogens & $7[4.2]$ & $1[1.5]$ & $8[3.4]$ \\
\hline Bacteroides fragilis & $3[1.8]$ & $0[0]$ & $3[1.3]$ \\
\hline Anaerococcus spp. & $2[1.2]$ & $0[0]$ & $2[0.9]$ \\
\hline Clostridium difficile & $1[0.6]$ & $1[1.5]$ & $2[0.9]$ \\
\hline Fusobacterium mortiferum & $1[0.6]$ & $0[0]$ & $1[0.4]$ \\
\hline Other pathogens & $44[26.7]$ & $17[25.4]$ & 61 [26.3] \\
\hline Enterococcus faecalis & $8[4.8]$ & $4[6]$ & $12[5.2]$ \\
\hline Pseudomonas aeruginosa & $7[4.2]$ & $1[1.5]$ & $8[3.4]$ \\
\hline Streptococcus dysgalactiae & $4[2.4]$ & $4[6]$ & $8[3.4]$ \\
\hline Propionibacterium acnes & $6[3.6]$ & $1[1.5]$ & $7[3]$ \\
\hline Streptococcus agalactiae & $4[2.4]$ & $0[0]$ & $4[1.7]$ \\
\hline Enterococcus faecium & $4[2.4]$ & $0[0]$ & $4[1.7]$ \\
\hline Streptococcus pneumoniae & $0[0]$ & $3[4.5]$ & $3[1.3]$ \\
\hline Streptococcus gallolyticus & $3[1.8]$ & $0[0]$ & $3[1.3]$ \\
\hline Streptococcus oralis & $1[0.6]$ & $1[1.5]$ & $2[0.9]$ \\
\hline Streptococcus pyogenes & $1[0.6]$ & $1[1.5]$ & $2[0.9]$ \\
\hline Acinetobacter baumannii & $0[0]$ & $1[1.5]$ & $1[0.4]$ \\
\hline Candida albicans & $1[0.6]$ & $0[0]$ & $1[0.4]$ \\
\hline Listeria monocytogenes & $1[0.6]$ & $0[0]$ & $1[0.4]$ \\
\hline Morganella morganii & $0[0]$ & $1[1.5]$ & $1[0.4]$ \\
\hline Streptococcus anginosus & $1[0.6]$ & $0[0]$ & $1[0.4]$ \\
\hline Streptococcus constellatus & $1[0.6]$ & $0[0]$ & $1[0.4]$ \\
\hline Streptococcus salivarius & $1[0.6]$ & $0[0]$ & $1[0.4]$ \\
\hline Streptococcus sanguinis & $1[0.6]$ & $0[0]$ & $1[0.4]$ \\
\hline
\end{tabular}

$P J /$ periprosthetic joint infection, $N J /$ native joint infection

Percentages relate to total detections of the respective group (PJI, NJl and Total)

${ }^{*}$ Percentages relate to the value of the line above

primarily designed for detecting variations in the pathogen spectrum between the two groups.

Indeed, several studies observed that pre-existing comorbidities, such as diabetes mellitus and renal insufficiency, increase the risk of infection after joint replacement, as well as mortality [23, 24]. Evidence for differing pathogen spectra depending on the presence of these diseases is weak. Our study results indicate a similar bacterial distribution in joint infections of patients with or without renal insufficiency or diabetes mellitus. 


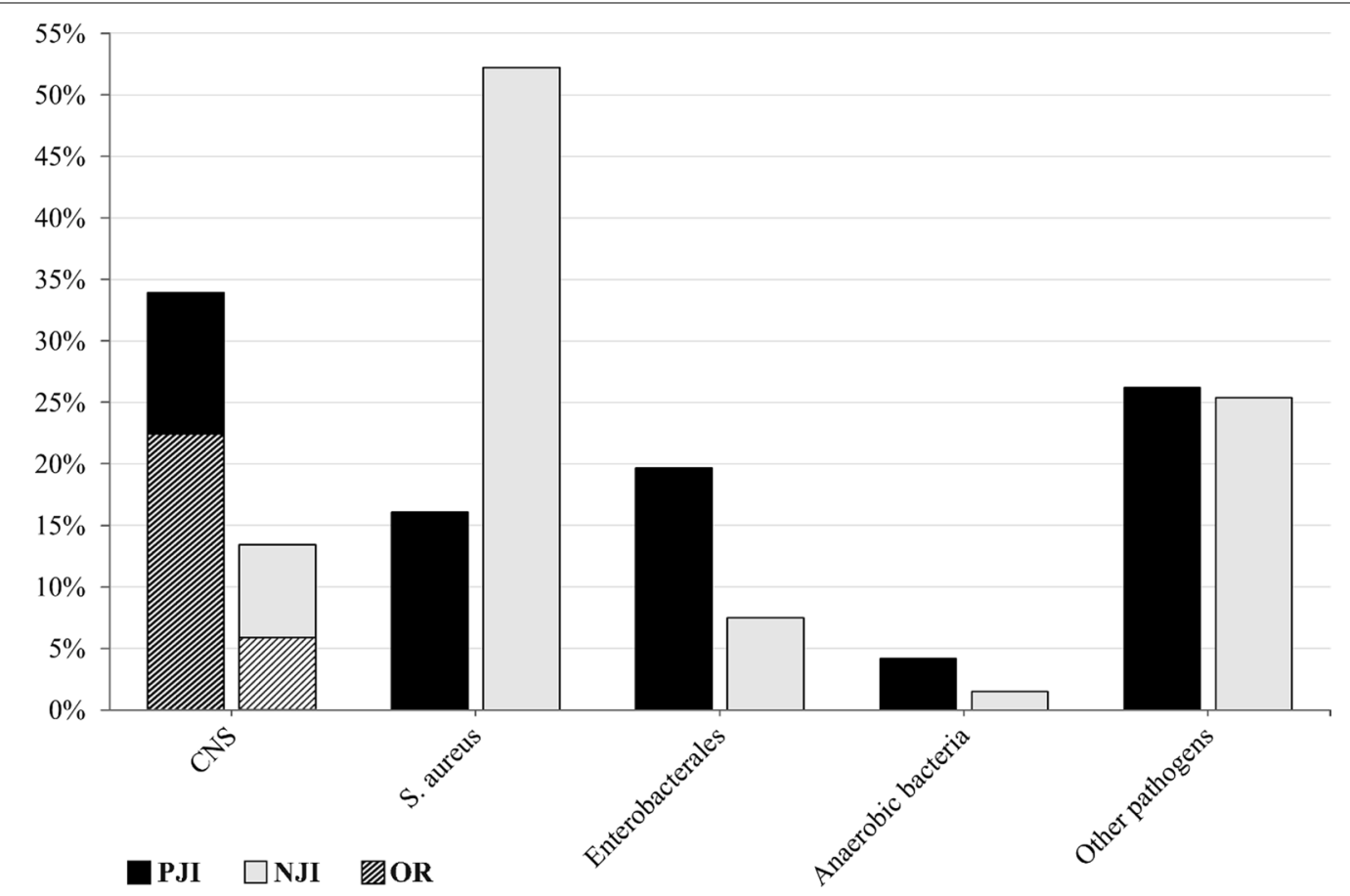

Fig. 1 Detection rates of pathogen classes in PJI and NJI. PJl: Periprosthetic joint infection. NJI: Native joint infection. OR: Oxacillin resistance. X-axis: pathogen classes. Y-axis: detection rates

While detecting potentially causative bacteria in joint infections is a key element in diagnostics, in addition to a proper surgical therapy, the patients' outcome largely depends on an adequate antimicrobial drug therapy. Early empiric antibiotic therapy is therefore considered a significant component in the treatment of both, NJIs and PJIs $[4,25]$. However, due to the heterogeneity of medical treatment concepts, evidence for a superior effectiveness of one specific calculated antibiotic regime in NJIs is lacking $[25,26]$. Regarding early antibiotic therapy in infections of prosthetic joints, the literature states diverse approaches as well $[27,28]$. Despite the knowledge of predominantly involved bacteria in PJIs and NJIs, consistent international guidelines for early antibiotic therapy are still missing.

Notably, CNS and S. aureus are the predominant pathogen types in both, periprosthetic and native joint infections. As PJI and NJI patients are usually initially treated by the same empiric antibiotic regime, the presence or absence of a joint prosthesis seems therefore not to be relevant with respect to early calculated anti-infective drug therapy concepts.

Nevertheless, novel aspects emerge from this current study. With a detection rate of $18.8 \%$ of Enterobacterales, their importance in PJIs may have been underestimated yet. Thus, it may be an option also to include antibiotics targeting gram-negative bacteria in early antibiotic therapy in PJI. In addition, we found that $2 / 3$ of CNS in prosthetic joint infections were oxacillin-resistant. Consequently, broad-spectrum coverage of these pathogens in empiric anti-infective medication, such as with vancomycin in the absence of contraindications, should be considered.

This study has some limitations. Regarding PJIs, we did not consider whether the synovial fluid analysis was performed in an acute or chronic infection, although differing pathogen spectra are known for these subgroups [3]. Furthermore, in NJIs, the primary focus of infection was not evaluated and possible differences in the microbial spectrum of iatrogenic, post-traumatic or haematogenous infections remain therefore uncertain. Samples were collected from closed joint aspirates only, and intraoperative culture results were not included in the microbiological analyses. Hence, there is a risk that the totality of pathogens actually involved in joint infections is not entirely represented in the study results. Finally, as this is a retrospective study, it is limited by its inherent methodological drawback.

\section{Conclusion}

Staphylococcus aureus and CNS are the predominantly involved microorganisms in PJIs and NJIs. Nevertheless, the high rate of oxacillin resistances in CNS, as well 
as the elevated detection rate of Enterobacterales, may necessitate a change in early antibiotic therapy in PJIs.

\begin{abstract}
Abbreviations
PJl: Periprosthetic joint infections; NJl: Native joint infections; CNS: Coagulasenegative Staphylococci; S. aureus: Staphylococcus aureus; S. epidermidis: Staphylococcus epidermidis; S. capitis: Staphylococcus capitis; S. hominis: Staphylococcus hominis; S. Iugdunensis: Staphylococcus lugdunensis; S. caprae: Staphylococcus caprae; E. coli: Escherichia coli; MRSA: Oxacillin-resistant S. aureus.
\end{abstract}

\section{Acknowledgements}

MS declares honoraria for lectures from CSL Behring. JL declares research grants from BBraun Aesculap, Mathys, Link, Smith\&Nephew and BiometZimmer and honoraria for lectures from BBraun Aesculap, Mathys, Link and Pfizer. $\mathrm{SL}, \mathrm{CK}, \mathrm{AT}$, and $\mathrm{KB}$ declare neither research grants nor honoraria.

\section{Authors' contributions}

Research design was contributed by MS, SL, KB, AT. Data acquisition was contributed by AT, SL. Analysis and interpretation of data were contributed by MS, SL, KB. Drafting the paper was contributed by MS, SL. Revising the paper critically was contributed by MS, KB, AT, JL, CK. Approval of the final version was contributed by MS, SL, KB, AT, JL, CK. All authors read and approved the final manuscript.

\section{Funding}

Open Access funding enabled and organized by Projekt DEAL.

\section{Availability of data and material}

The datasets used and analyzed during the current study are available from the corresponding author on reasonable request.

\section{Declarations}

\section{Ethics approval and consent to participate}

The study was conducted in accordance with the provisions of the Declaration of Helsinki. Due to the anonymized data collection and the retrospective design, no ethics application was necessary for the study conduct according to Saxonian legislation.

\section{Consent for publication}

All authors have read and approved the final manuscript and consented to publication.

\section{Competing interests}

The authors declare that they have no competing interests.

\section{Author details}

${ }^{1}$ University Centre of Orthopaedic, Trauma and Plastic Surgery, University Hospital Carl Gustav Carus Dresden, TU Dresden, Fetscherstraße 74, 01307 Dresden, Germany. ${ }^{2}$ Department of Medical Microbiology and Hygiene, Medical Faculty Carl Gustav Carus, TU Dresden, Dresden, Germany.

Received: 19 September 2021 Accepted: 15 November 2021 Published online: 06 January 2022

\section{References}

1. Nemes S, Gordon M, Rogmark C, Rolfson O. Projections of total hip replacement in Sweden from 2013 to 2030. Acta Orthop. 2014;85(3):238-43.

2. Huotari $K$, Peltola $M$, Jamsen $E$. The incidence of late prosthetic joint infections: a registry-based study of 112,708 primary hip and knee replacements. Acta Orthop. 2015;86(3):321-5.

3. Garcia-Arias M, Balsa A, Mola EM. Septic arthritis. Best Pract Res Clin Rheumatol. 2011;25(3):407-21.

4. Roerdink RL, Huijbregts $H$, van Lieshout AWT, Dietvorst $M$, van der Zwaard BC. The difference between native septic arthritis and prosthetic joint infections: a review of literature. J Orthop Surg (Hong Kong). 2019;27(2):2309499019860468.

5. Cataldo MA, Petrosillo N, Cipriani M, Cauda R, Tacconelli E. Prosthetic joint infection: recent developments in diagnosis and management. J Infect. 2010;61(6):443-8.

6. Zmistowski B, Karam JA, Durinka JB, Casper DS, Parvizi J. Periprosthetic joint infection increases the risk of one-year mortality. J Bone Jt Surg Am. 2013;95(24):2177-84

7. Kunutsor SK, Whitehouse MR, Blom AW, Beswick AD, Team I. Re-infection outcomes following one- and two-stage surgical revision of infected hip prosthesis: a systematic review and meta-analysis. PLoS ONE. 2015;10(9):e0139166.

8. Browne JA, Cancienne JM, Novicoff WM, Werner BC. Removal of an infected hip arthroplasty is a high-risk surgery: putting morbidity into context with other major nonorthopedic operations. J Arthroplasty. 2017:32(9):2834-41.

9. Pavoni GL, Giannella M, Falcone M, Scorzolini L, Liberatore M, Carlesimo $B$, et al. Conservative medical therapy of prosthetic joint infections: retrospective analysis of an 8-year experience. Clin Microbiol Infect. 2004;10(9):831-7.

10. Geipel U. Pathogenic organisms in hip joint infections. Int J Med Sci. 2009:6(5):234-40.

11. Veerachamy S, Yarlagadda T, Manivasagam G, Yarlagadda PK. Bacterial adherence and biofilm formation on medical implants: a review. Proc Inst Mech Eng Part H J Eng Med. 2014;228(10):1083-99.

12. Aggarwal VK, Bakhshi H, Ecker NU, Parvizi J, Gehrke T, Kendoff D. Organism profile in periprosthetic joint infection: pathogens differ at two arthroplasty infection referral centers in Europe and in the United States. J Knee Surg. 2014;27(5):399-406.

13. Davidson DJ, Spratt D, Liddle AD. Implant materials and prosthetic joint infection: the battle with the biofilm. EFORT Open Rev. 2019:4(11):633-9.

14. Cunningham R, Cockayne A, Humphreys H. Clinical and molecular aspects of the pathogenesis of Staphylococcus aureus bone and joint infections. J Med Microbiol. 1996:44(3):157-64.

15. Gramlich Y, Klug A, Walter G, Kremer M, Hoffmann R, Kemmerer M. Septic arthritis of native shoulder and knee joint: what are the differences in bacterial spectrum, treatment, and outcome? Surg Infect (Larchmt). 2020:21(4):391-7.

16. Lentino JR. Prosthetic joint infections: bane of orthopedists, challenge for infectious disease specialists. Clin Infect Dis. 2003:36(9):1157-61.

17. Li ZL, Hou YF, Zhang BQ, Chen YF, Wang Q, Wang K, et al. Identifying common pathogens in periprosthetic joint infection and testing drugresistance rate for different antibiotics: a prospective, single center study in Beijing. Orthop Surg. 2018;10(3):235-40.

18. Sigmund IK, Winkler T, Onder N, Perka C, Renz N, Trampuz A. Complications of resection arthroplasty in two-stage revision for the treatment of periprosthetic hip joint infection. J Clin Med. 2019;8(12):2224.

19. Ryan MJ, Kavanagh R, Wall PG, Hazleman BL. Bacterial joint infections in England and Wales: analysis of bacterial isolates over a four year period. $\mathrm{Br}$ J Rheumatol. 1997;36(3):370-3.

20. Dubost JJ, Soubrier M, De Champs C, Ristori JM, Bussiere JL, Sauvezie $B$. No changes in the distribution of organisms responsible for septic arthritis over a 20 year period. Ann Rheum Dis. 2002;61(3):267-9.

21. Siu KT, Ng FY, Chan PK, Fu HC, Yan CH, Chiu KY. Bacteriology and risk factors associated with periprosthetic joint infection after primary total knee arthroplasty: retrospective study of 2543 cases. Hong Kong Med J. 2018:24(2):152-7.

22. Hsieh PH, Lee MS, Hsu KY, Chang YH, Shih HN, Ueng SW. Gram-negative prosthetic joint infections: risk factors and outcome of treatment. Clin Infect Dis. 2009:49(7):1036-43.

23. Jamsen E, Nevalainen P, Eskelinen A, Huotari K, Kalliovalkama J, Moilanen T. Obesity, diabetes, and preoperative hyperglycemia as predictors of periprosthetic joint infection: a single-center analysis of 7181 primary hip and knee replacements for osteoarthritis. J Bone Jt Surg Am. 2012;94(14):e101.

24. Erkocak OF, Yoo JY, Restrepo C, Maltenfort MG, Parvizi J. Incidence of infection and inhospital mortality in patients with chronic renal failure after total joint arthroplasty. J Arthroplasty. 2016;31(11):2437-41.

25. Mathews CJ, Weston VC, Jones A, Field M, Coakley G. Bacterial septic arthritis in adults. Lancet. 2010;375(9717):846-55. 
26. Stengel D, Bauwens K, Sehouli J, Ekkernkamp A, Porzsolt F. Systematic review and meta-analysis of antibiotic therapy for bone and joint infections. Lancet Infect Dis. 2001;1(3):175-88.

27. Moran E, Masters S, Berendt AR, McLardy-Smith P, Byren I, Atkins BL. Guiding empirical antibiotic therapy in orthopaedics: the microbiology of prosthetic joint infection managed by debridement, irrigation and prosthesis retention. J Infect. 2007;55(1):1-7.

28. Van Erp JHJ, Heineken AC, Van Wensen RJA, Van Kempen R, Hendriks JGE, Wegdam-Blans M, et al. Optimization of the empirical antibiotic choice during the treatment of acute prosthetic joint infections: a retrospective analysis of 91 patients. Acta Orthop. 2019;90(5):455-9.

\section{Publisher's Note}

Springer Nature remains neutral with regard to jurisdictional claims in published maps and institutional affiliations.

- fast, convenient online submission

- thorough peer review by experienced researchers in your field

- rapid publication on acceptance

- support for research data, including large and complex data types

- gold Open Access which fosters wider collaboration and increased citations

- maximum visibility for your research: over $100 \mathrm{M}$ website views per year

At $\mathrm{BMC}$, research is always in progress.

Learn more biomedcentral.com/submissions 